\title{
Article \\ Constructing 1D Boron Chains in the Structure of Transition Metal Monoborides for Hydrogen Evolution Reactions
}

\author{
Yanli Chen ${ }^{1,2,3} \mathbb{D}$, Yanping Ye ${ }^{1}$, Qiang Tao ${ }^{4} \mathbb{D}$, Lihua Yang ${ }^{1,2,3}$, Jiaen Cheng ${ }^{4}$, Xiaoyan Liu ${ }^{1,2,3}$, Jian Cao ${ }^{1,2,3}$, \\ Hougang Fan 1,2,3, Maobin Wei 1,2,3, Pinwen Zhu ${ }^{4, *}$, Lili Yang 1,2,3,* and Jinghai Yang 1,2,3,* \\ 1 Key Laboratory of Functional Materials Physics and Chemistry of the Ministry of Education, \\ Jilin Normal University, Changchun 130103, China; ylchen@jlnu.edu.cn (Y.C.); ye997997@163.com (Y.Y.); \\ yanglh@jlnu.edu.cn (L.Y.); liuxiaoyan1437@163.com (X.L.); caojian_928@163.com (J.C.); \\ fanhougang@jlnu.edu.cn (H.F.); jlsdzccw@126.com (M.W.) \\ 2 National Demonstration Center for Experimental Physics Education, Jilin Normal University, \\ Siping 136000, China \\ 3 Key Laboratory of Preparation and Application of Environmental Friendly Materials Ministry of Education, \\ Jilin Normal University, Changchun 130103, China \\ 4 State Key Laboratory of Superhard Materials, Jilin University, Changchun 130012, China; \\ qiangtao@jlu.edu.cn (Q.T.); chengje2019@163.com (J.C.) \\ * Correspondence: zhupw@jlu.edu.cn (P.Z.); llyang@jlnu.edu.cn (L.Y.); jhyang1@jlnu.edu.cn (J.Y.)
}

Citation: Chen, Y.; Ye, Y.; Tao, Q.; Yang, L.; Cheng, J.; Liu, X.; Cao, J.; Fan, H.; Wei, M.; Zhu, P.; et al. Constructing 1D Boron Chains in the Structure of Transition Metal Monoborides for Hydrogen Evolution Reactions. Catalysts 2021, 11, 1265. https://doi.org/10.3390/catal11111265

Received: 29 September 2021

Accepted: 19 October 2021

Published: 21 October 2021

Publisher's Note: MDPI stays neutral with regard to jurisdictional claims in published maps and institutional affiliations.

Copyright: (c) 2021 by the authors. Licensee MDPI, Basel, Switzerland. This article is an open access article distributed under the terms and conditions of the Creative Commons Attribution (CC BY) license (https:/ / creativecommons.org/licenses/by/ $4.0 /)$.

\begin{abstract}
The forms of boron atoms are many and varied in the structure of transition metal borides (TMBs). The form of boron atoms determines the structure, morphology, and properties of borides. Herein, transition metal monoborides ( $\mathrm{CrB}$ and $\mathrm{WB}$ ) with different arrangement of one-dimensional (1D) boron chains were synthesized under high pressures and high temperatures. The 1D boron chains between the interlayers of $\mathrm{CrB}$ are parallel to one another, while the $1 \mathrm{D}$ boron chains between the interlayers of WB are perpendicular to one another. The morphologies of $\mathrm{CrB}$ and $\mathrm{WB}$ also show large differences due to the difference in $1 \mathrm{D}$ boron chain arrangement. As electrocatalysts for hydrogen evolution reactions (HERs), $\mathrm{CrB}$ and WB show good catalysis activity and durability. WB has the smallest overpotential $(210 \mathrm{mV})$ and Tafel slope $\left(90.09 \mathrm{mV} \mathrm{dec}^{-1}\right)$, which is mainly attributed to the intercrossing boron chains improving the electrical properties of $\mathrm{WB}$, as well as the $5 \mathrm{~d}$ electrons of $\mathrm{W}$ being more chemically active. The TOF value of WB is $1.35 \mathrm{~s}^{-1}$, proving that WB has a higher intrinsic catalytic activity during HERs. This work provides a data reference for the development of high-efficiency electrocatalysts.
\end{abstract}

Keywords: transition metal monoborides; 1D boron chains; high pressure and high temperature; electrocatalyst; hydrogen evolution reaction; periodic bond chain theory

\section{Introduction}

Hydrogen, as a non-carbon energy carrier with high energy density and zero-pollution emissions, has attracted widespread attention in the past decade [1-3]. Although hydrogen is the most abundant element in the universe, it is mainly stored as a chemical compound in the most profuse resource on Earth, i.e., water. To this end, hydrogen from water splitting is the key element to develop hydrogen energy in the future. Water electrolysis could meet all the requirements of clean, renewable energy sources, while the electricity could be driven by solar, wind, or other renewable energy sources [4,5]. In order to improve the conversion efficiency of water electrolysis, an appropriate electrocatalyst is necessary. As we know, noble metals (e.g., Pt, Pd, etc.) have the best hydrogen evolution reaction (HER) performance in acidic solutions, but their high cost and rarity are not suitable for large-scale application [6]. Therefore, it is urgent to develop low-cost, high-efficiency, and stable electrocatalysts to replace noble metals. Over the past decade, more and more catalysts have been developed, including carbides, sulfides, nitrides, phosphides, borides, etc. [7-9]. 
Among them, transition metal borides (TMBs) have attracted extensive attention in the field of electrocatalytic water splitting, because of their excellent electrical properties and abundant structural forms-especially for HER. TMBs such as MoB, CoB, NiB, FeB, etc., have been reported [10-23], showing excellent catalytic performances in the watersplitting field. While some of these catalysts cover the intrinsic mechanism of TMBs for HERs, they have no specific structures other than amorphous. Although several TMBs with certain structures also indicate superior HER performance, others do not. One of the reasons for this is that, in addition to the transition metal, the form of boron atoms in the compound also has a certain influence on the catalytic performance. The most typical catalyst influenced by the form of boron atoms is molybdenum diboride $\left(\mathrm{MoB}_{2}\right)$, which has two phase structures, only differing in the arrangement of boron atoms. In the metastable phase $\left(\mathrm{AlB}_{2}\right.$-type), the present form of boron atoms is a two-dimensional (2D) graphenelike borophene structure, while in the stable phase, boron atoms also exist in the form of a puckered boron layer as well as the 2D graphene-like borophene structure. Experimental and theoretical results confirm that the 2D graphene-like borophene structure is the main factor that improves the catalytic performance during the HER process [24]. However, the intrinsic influence of other forms of boron atoms is rarely reported, e.g., one-dimensional (1D) boron chains or 3D boron skeletons. Uncovering the inner mechanism of TMBs for HERs, based on the form of boron, is significant.

In the boride system, 3D boron skeletons are always difficult to fabricate, because of boron's lack of electrons. Nevertheless, boron atoms can also exist in the form of onedimensional (1D) boron chains in the structure of transition metal monoborides. In our previous report, we found that MoB has two phase structures, with the difference being in the arrangement of 1D boron chains. Therefore, the synthesis of metastable-phase $\mathrm{MoB}$ with parallel boron chains requires a very high reaction temperature, which presents difficulties in the experimental operation [25]. However, by changing transition metal elements, compounds with two kinds of boron chains can be obtained under relatively mild conditions, and the influence of 1D boron chains on electrocatalytic activity can be explored.

Therefore, in this work, we synthesized pure phases of $\mathrm{CrB}$ and WB under high pressure and high temperature (HPHT). The structures and morphologies of $\mathrm{CrB}$ and WB were confirmed. In addition, the electrocatalytic activity of transition metal monoborides for HERs was conducted in acidic solution, and the differences in the HER performance of $\mathrm{CrB}$ and WB were analyzed. The influence of $1 \mathrm{D}$ boron chains and the effect of different metal atoms for HERs were studied. The above results prove that the transition metal borides are potential catalysts to replace noble metals, and provide data to support the development of hydrogen energy in the future.

\section{Results and Discussion}

Transition metal monoborides were synthesized by HPHT as described in our previous report (Scheme 1; for more details, see the Section 3). The samples obtained resembled tablets in appearance. The crystal structures of transition metal monoborides were obtained via powder X-ray diffraction (XRD). As can be seen from Figure 1a, CrB and WB were successfully synthesized; the crystal structures of $\mathrm{CrB}$ and WB belong to orthorhombic $(\mathrm{Cmcm})$ and tetragonal ( $\left.\mathrm{I}_{1} / \mathrm{amd}\right)$ systems, respectively, which is consistent with previous reports [26-30]. As described in these papers, the structural formulae of $\mathrm{CrB}$ and WB are shown in Figure 1b,c, respectively. $\mathrm{CrB}$ and WB have similar crystal structures, composed of a 3D metal frame and 1D boron chains. However, the interlayer 1D boron chains are arranged in parallel for $\mathrm{CrB}$, while they are perpendicular to one another in $\mathrm{WB}$. 


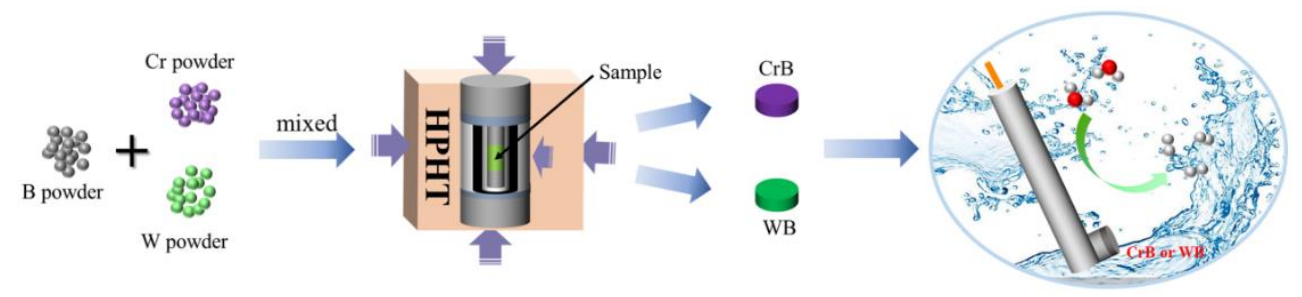

Scheme 1. Preparation process and HER diagram of $\mathrm{CrB}$ and WB.

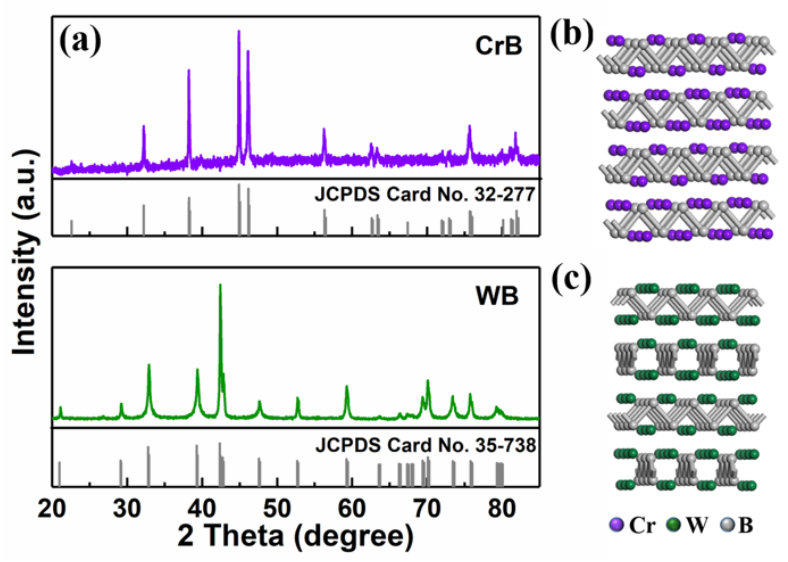

Figure 1. (a) XRD pattern of $\mathrm{CrB}$ and WB. The structural formulae of (b) $\mathrm{CrB}$ and (c) WB.

The surface morphology of the samples was investigated via field-emission scanning electron microscopy (FESEM). The surface of $\mathrm{CrB}$ is composed of grains of micron size, and it exhibits a step-growth mechanism that shows two-dimensional steps, as shown by the blue dotted line in Figure 2a. When zooming in on the surface of $\mathrm{CrB}$, a dense surface is observed, as with all previous samples prepared under HPHT (Figure 2b). Meanwhile, WB has a relatively flat surface with pores of different sizes (Figure 2e). As shown in Figure $2 \mathrm{f}$, the internal morphology of WB was observed through the pores, and it was found that WB is composed of nanoparticles with grain sizes of $\sim 200 \mathrm{~nm}$. The existence of pores may be due to the fact that WB has stronger mechanical properties, preventing the elimination of air to the surface of the sample under HPHT. The difference in grain sizes between $\mathrm{CrB}$ and $\mathrm{WB}$ lies in the different arrangement of the 1D boron chains. According to the $\mathrm{PBC}$ theory, there is a strong covalent bond along the direction of the 1D boron chain, so there is a faster growth rate in this direction [31-33]. In $\mathrm{CrB}$, the $1 \mathrm{D}$ boron chains between the interlayers are arranged in parallel to one another, so they grow in step mode, and eventually produce micrometer-size morphology. However, the 1D boron chains between the interlayers of WB are perpendicular to one another; thus, in the process of grain growth, the $1 \mathrm{D}$ boron chains between the interlayers inhibit one another's growth rates, limiting the growth of grains and forming nano-scale grains. High-resolution transmission electron microscopy (HRTEM) was used to observe finer structural information. Both CrB and WB show good crystallinity in Figure 2c,g, respectively. The crystal surface information was characterized by inverse fast Fourier transformation (IFFT) and line-scanning intensity profile. The line-scanning intensity profile obtained from the area is highlighted by the green frame and purple frame in the inset of Figure $2 d, h$, respectively. The spacing of $0.279 \mathrm{~nm}$ corresponds to the (110) crystal plane in $\mathrm{CrB}$, and the spacing of $0.307 \mathrm{~nm}$ matches the (101) crystal plane in WB. All of the results confirm that CrB and WB were successfully synthesized under HPHT. 


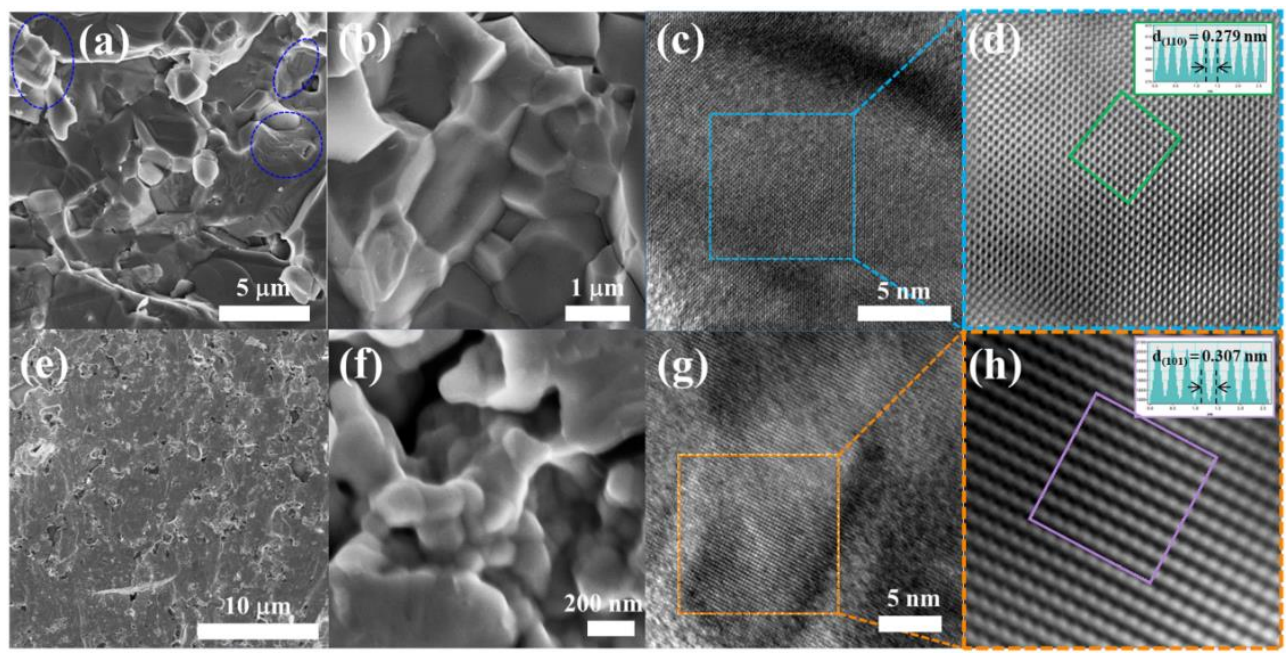

Figure 2. (a,b) SEM images of CrB. (c) HRTEM image of CrB. (d) The IFFT graph of the dotted box in (c); inset is the line-scanning intensity profile of the green box. (e,f) SEM images of WB. (g) HRTEM image of WB. (h) The IFFT graph of the dotted box in (g); inset is the line-scanning intensity profile of the purple box.

The valence and bonding modes of $\mathrm{CrB}$ and $\mathrm{WB}$ were characterized via $\mathrm{X}$-ray photoelectron spectroscopy (XPS). Figure 3a,d show the XPS spectra of $\mathrm{CrB}$ and WB. The associated peaks of elements appeared in both $\mathrm{CrB}$ and $\mathrm{WB}$. In addition, $\mathrm{O}$ peaks were observed, which may be from the result of surface oxidation $[34,35]$. The determination of metal-B bonding refers to the previous literature, where it was reported that the binding energy position of metal-B bonding is slightly higher than that of pure metal [36]. Hence, the bonding of $\mathrm{Cr}-\mathrm{B}$ located at 574.44 and $583.69 \mathrm{eV}$ corresponds to $2 \mathrm{p}_{3 / 2}$ and $2 \mathrm{p}_{1 / 2}$, respectively (Figure $3 \mathrm{~b}$ ) - higher than that of pure metal $\mathrm{Cr}(574.2 \mathrm{eV})$ [37]. The other pairs of peaks at 576.9 and $586.47 \mathrm{eV}$ belong to $\mathrm{Cr}-\mathrm{O}$ bonding [38], whereas the $\mathrm{B}$ shows two peaks of B-Cr and B-O at 187.63 and $192 \mathrm{eV}$, respectively (Figure 3c). As shown in Figure 3e, a pair of binding energies slightly higher than the peaks of pure metal $\mathrm{W}$ are located at 31.18 and $33.32 \mathrm{eV}$, which are attributed to to $4 \mathrm{f}_{7 / 2}$ and $4 \mathrm{f}_{5 / 2}$ of $\mathrm{W}-\mathrm{B}$ bonding, respectively [39]. The pair of peaks at the higher binding energy belong to $\mathrm{W}-\mathrm{O}$ bonding [40]. Similar B peaks also appeared in WB. The peak at a higher binding energy position was comparable to the $\mathrm{B}$ peak of $\mathrm{CrB}$, indicating that the $1 \mathrm{D}$ boron chain with perpendicular arrangement needs less charge transfer to exist stably, compared with the $1 \mathrm{D}$ boron chain with parallel arrangement.

The electrochemical HER performance of $\mathrm{CrB}$ and $\mathrm{WB}$ at $0.5 \mathrm{M} \mathrm{H}_{2} \mathrm{SO}_{4}(\mathrm{pH} 0)$ was determined by employing a standard three-electrode system on a $\mathrm{CH}$ Instruments 760E electrochemical analyzer. For comparison, $\mathrm{B}$ powder, $\mathrm{Cr}$ sheets, and $\mathrm{W}$ wire were also studied under the same conditions. The polarization curves of HER for different catalysts are shown in Figure 4a. The HER activity of B powder was negligible. The overpotential of $\mathrm{CrB}$ and $\mathrm{WB}$ at a current density of $10 \mathrm{~mA} \mathrm{~cm}^{-2}\left(\eta_{10}\right)$ was 347 and $210 \mathrm{mV}$, respectively, while those of metal $\mathrm{Cr}$ and $\mathrm{W}$ were 582 and $526 \mathrm{mV}$, respectively. The performance of WB was consistent with Zou's report [41]. The Tafel slopes were calculated from the polarization curve (Figure $4 \mathrm{~b}$ ), showing that the Tafel slopes of $\mathrm{CrB}$ and WB were 110.59 and $90.06 \mathrm{mV} \mathrm{dec}^{-1}$, respectively-smaller than those of B powder $\left(191.05 \mathrm{mV} \mathrm{dec}^{-1}\right), \mathrm{Cr}$ sheets $\left(150.37 \mathrm{mV} \mathrm{dec}^{-1}\right)$, and $\mathrm{W}$ wire $\left(139.93 \mathrm{mV} \mathrm{dec}^{-1}\right)$. The results suggest that the HER kinetics of metal $\mathrm{Cr}$ and $\mathrm{W}$ are accelerated after boronization. Meanwhile, the exchange current density $\left(j_{0}\right)$ of $\mathrm{CrB}$ and $\mathrm{WB}$ was calculated according to the linear region of the extrapolated Tafel slope to characterize the intrinsic HER activity. The $j_{0}$ of $\mathrm{CrB}$ and WB was 0.017 and $0.776 \mathrm{~mA} \mathrm{~cm}^{-2}$, respectively. Both Tafel slopes and $j_{0}$ indicated that WB has more favorable kinetics than $\mathrm{CrB}$ for HERs. Electrochemical impedance spectroscopy (EIS) also revealed that the electron transfer resistance $\left(R_{c t}\right)$ of WB is much lower than that of 
$\mathrm{CrB}$ (Figure 4c), further demonstrating that WB has much faster charge transfer during the HER process, and accelerates the hydrogen evolution reaction. Figure $4 \mathrm{~d}$ is obtained using $\eta_{10}$, Tafel slope and $R_{c t}$ as functional coordinates, indicating that $W B$ is the optimal electrocatalyst with various indices.
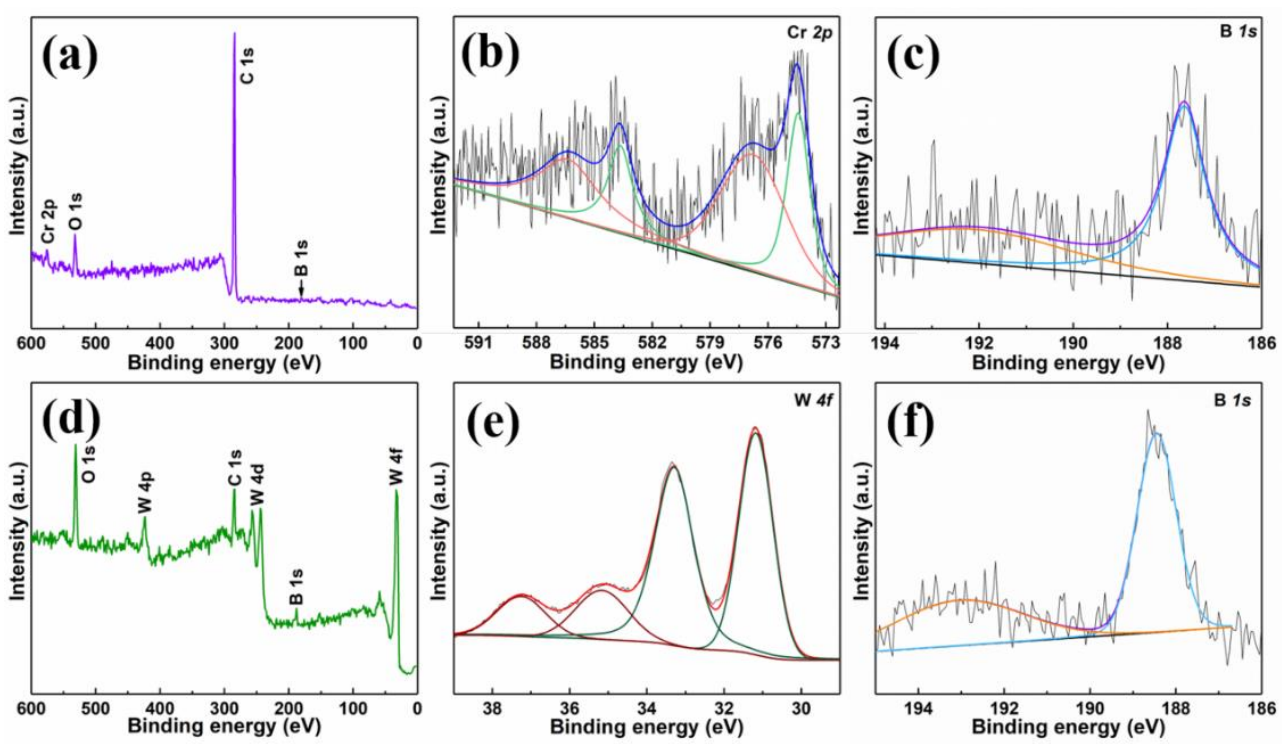

Figure 3. XPS survey spectra of (a) CrB and (d) WB. (b) Cr 2p, (c) B 1s of CrB, (e) W 4f, and (f) B 1s of WB.

The electrochemical surface area (ECSA) was used to assess the number of HER active sites on $\mathrm{CrB}$ and WB $[42,43]$. The double-layer capacitance $\left(\mathrm{C}_{\mathrm{dl}}\right)$ of the catalyst is proportional to the value of ECSA [44,45]. Thus, the $\mathrm{C}_{\mathrm{dl}}$ values of $\mathrm{CrB}$ and $\mathrm{WB}$ are shown in Figure 4e. The $C_{\mathrm{dl}}$ value of $\mathrm{WB}$ is $8.36 \mathrm{mF} \mathrm{cm}^{-2}$, which is higher than that of $\mathrm{CrB}\left(1.72 \mathrm{mF} \mathrm{cm}^{-2}\right)$. The larger ECSA is attributed to the pores on the WB surface (Figure 2e,f), which are conducive to the immersion of electrolytes, enabling the exposure of more active sites to participate in the HER. In order to investigate the intrinsic HER activity of each active site, we further calculated the $\mathrm{H}_{2}$ turnover frequency (TOF) of $\mathrm{CrB}$ and WB (Figure $4 \mathrm{f}$ ). When the overpotential is $-0.3 \mathrm{~V}$ vs. RHE, the TOF value of WB is $1.35 \mathrm{~s}^{-1}$, while that of $\mathrm{CrB}$ is only $0.17 \mathrm{~s}^{-1}$. The results show that the intrinsic activity of $\mathrm{WB}$ is much better than that of $\mathrm{CrB}$, which may be due to the fact that the chemical activity of $5 \mathrm{~d}$ electron in $\mathrm{W}$ is higher than that of $3 \mathrm{~d}$ electron in $\mathrm{Cr}$, and it can undergo a rapid adsorption/desorption reaction in the hydrogen evolution process. Furthermore, the amount of hydrogen generated was tested with different times for $\mathrm{CrB}$ and WB (Figure 4g). The results indicate that WB has a higher hydrogen generation rate than $\mathrm{CrB}$. For electrocatalysts, another important evaluation index is long-term stability. At a constant current density of $10 \mathrm{~mA} \mathrm{~cm}{ }^{-2}$, the overpotential of $\mathrm{CrB}$ and WB were maintained for approximately $12 \mathrm{~h}$ without significant activity loss (Figure $4 \mathrm{~h}$ ). To sum up, the transition metal monoborides synthesized under HPHT show good HER activity under acidic conditions, while WB shows excellent catalytic activity. 

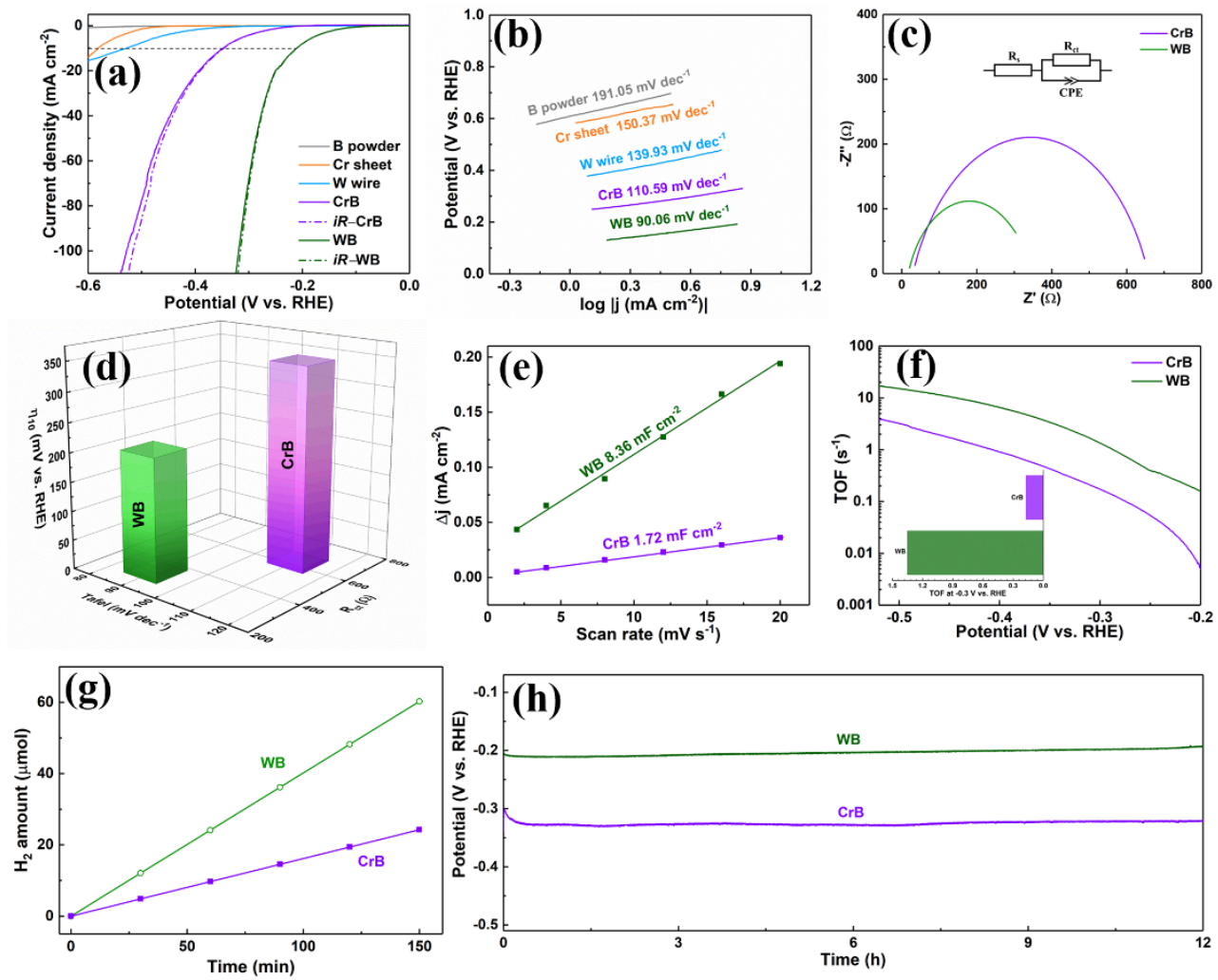

Figure 4. (a) Polarization curves of amorphous B powder, $\mathrm{Cr}$ sheets, $\mathrm{W}$ wire, $\mathrm{CrB}$, and WB. (b) Corresponding Tafel plots. (c) Nyquist plots of CrB and WB at $-0.3 \mathrm{~V}$ vs. RHE. (d) Overpotential, Tafel slope and $\mathrm{R}_{\mathrm{ct}}$ comparison of $\mathrm{CrB}$ and WB. (e) The double-layer capacitance $\left(\mathrm{C}_{\mathrm{dl}}\right)$ of $\mathrm{CrB}$ and WB. (f) Calculated TOF for $\mathrm{CrB}$ and $\mathrm{WB}$; inset shows the TOF value at $-0.3 \mathrm{~V}$ vs. RHE. (g) The amount of hydrogen generated for $\mathrm{CrB}$ and WB. (h) The stability test of $\mathrm{CrB}$ and $\mathrm{WB}$ at a current density of $10 \mathrm{~mA} \mathrm{~cm}^{-2}$.

\section{Materials and Methods}

\subsection{Materials}

Metal chromium powder (99.9\%), metal tungsten powder $(99.9 \%)$, amorphous boron powder $(99.9 \%)$, chromium sheet $(99.95 \%)$, tungesten wire $(99.99 \%)$ were purchased from Aladdin. Sulfuric acid (98\%) and silver paste were purchased from Beijing Chemical Factory. Potassium hydroxide (85\%) was obtained from Tianjin Chemical Industry Research Institute. Highly purified water ( $>18 \mathrm{M} \Omega \mathrm{cm}$ resistivity) was provided by a PALL PURELAB Plus system.

\subsection{Materials Synthesis}

Transition metal monoborides were synthesized under HPHT. For CrB, known amounts of metal chromium powder $(99.9 \%)$ and amorphous boron powder $(99.9 \%)$ were mixed at a molar ratio of 1:1.05, and the powders were mixed in an agate mortar for more than $3 \mathrm{~h}$ to ensure a uniform mixture. The mixed powder was cold-pressed into a tablet with a diameter of $4 \mathrm{~mm}$ and a height of $3 \mathrm{~mm}$. The tablet was then placed in a cubic anvil HPHT apparatus $(6 \times 14,400 \mathrm{KN})$ at $5 \mathrm{GPa}$ and $1600{ }^{\circ} \mathrm{C}$ for a holding time of $15 \mathrm{~min}$. The details of the HPHT apparatus and assembly are provided in our previous report [46]. For the synthesis of $\mathrm{WB}$, the operation was similar to that of $\mathrm{CrB}$, except that the chromium powder was replaced with metal tungsten powder, the molar ratio of the starting material was $1: 1$, and the reaction temperature was $1400^{\circ} \mathrm{C}$. 


\subsection{Characterization}

The phased structure of the transition metal monoborides was determined via powder X-ray diffraction (XRD) using $\mathrm{Cu} \mathrm{K} \alpha(\lambda=1.5418)$ radiation in a Rigaku SmartLab SE instrument. The surface composition and chemical states of the synthesized samples were analyzed via X-ray photoelectron spectroscopy (XPS) on an ESCA LAB 250 X-ray photoelectron spectrometer with $\mathrm{Al} \mathrm{K} \alpha$ radiation $(\mathrm{h} v=1486.6 \mathrm{eV})$ as the $\mathrm{X}$-ray source. Field-emission scanning electron microscopy (FESEM, FEI Magellan 400 operating at $18 \mathrm{kV}$ ) and high-resolution transmission electron microscopy (HRTEM, JEM-2200FS operating at $200 \mathrm{kV}$ ) were used to observe the surface morphology and micromorphology of the synthesized samples.

\subsection{Preparation of Working Electrode}

The preparation of the working electrode was similar to that in our previous report [14]. The sample tablet was anchored on the L-shaped copper electrode with conductive silver slurry. After the slurry was dried, the exposed silver slurry and copper electrode were wrapped and sealed with modified acrylate adhesive. The test area of the working electrode was determined using a Leica M125 C instrument.

\subsection{Electrochemical Measurements}

All electrochemical measurements were performed using a $\mathrm{CH}$ Instrument (Model $760 \mathrm{E}$ ) with a standard three-electrode system under $0.5 \mathrm{M} \mathrm{H}_{2} \mathrm{SO}_{4}$ electrolytes ( $\mathrm{pH} 0$ ). A high-density graphite rod and saturated calomel electrode (SCE) were used as the counter electrode and reference electrode, respectively. During the experimental testing, the electrolyte needed to be saturated with $\mathrm{N}_{2}$. The potential was calibrated against the reversible hydrogen electrode (RHE) in this work. During the linear scan voltammogram (LSV) measurements, the scan rate was set to be $2 \mathrm{mV} \mathrm{s}^{-1}$, and the experimental data were iR corrected. The Tafel slope and exchange current density were obtained by extrapolating the polarization curve according to the following formula: $\eta=\mathrm{a}+$ blog $j$ [47-49]. Electrochemical impedance spectroscopy (EIS) was carried out at $-0.3 \mathrm{~V}$ vs. RHE with $5 \mathrm{mV}$ amplitude, and at a frequency range from $10^{6}$ to $1 \mathrm{~Hz}$. The electrochemical surface area was investigated via cyclic voltammograms $(\mathrm{CV})$ at various scan rates $(2,4,8,12,16$, and $\left.20 \mathrm{mV} \mathrm{s}^{-1}\right)$. The value of double-layer capacitance $\left(\mathrm{C}_{\mathrm{dl}}\right)$ was obtained by calculating the slope between the $\Delta j=j_{\text {anodic }}-j_{\text {cathodic }}$ and scan rates. The turnover frequency (TOF) was calculated as described in previous reports [50]. Since the catalytic active site is uncertain, according to previous reports, we conservatively considered the top site of the metal to be the catalytic active site [41].

\section{Conclusions}

In conclusion, we can report that $\mathrm{CrB}$ and $\mathrm{WB}$ were successfully synthesized under HPHT. The only structural difference between $\mathrm{CrB}$ and $\mathrm{WB}$ is the arrangement of the $1 \mathrm{D}$ boron chains. In $\mathrm{CrB}$, the boron chains between interlayers are parallel to one another, while in $\mathrm{WB}$, the boron chains are perpendicular to one another. It is because of the different arrangement of the $1 \mathrm{D}$ boron chains that the micromorphology is characterized by micron size and nanometer size in $\mathrm{CrB}$ and $\mathrm{WB}$, respectively. The transition metal monoborides exhibit excellent catalytic activity and durability for HERs under acidic conditions. Of the two, WB has a smaller overpotential of $210 \mathrm{mV}$, a smaller Tafel slope $\left(90.09 \mathrm{mV} \mathrm{dec}^{-1}\right)$, a smaller $\mathrm{R}_{\mathrm{ct}}(326.5 \Omega)$, a larger ECSA $\left(8.36 \mathrm{mF} \mathrm{cm}^{-2}\right)$, and better durability. TOF results also confirmed that the HER activity of the active site in WB is higher than that of $\mathrm{CrB}$. The best catalytic activity is generally shown by nanomaterials rather than bulk materials at present. Combined with the results of this work, transition metal monoboride catalysts have tremendous potential for improvement. Transition metal borides will become a promising kind of electrocatalyst candidate for the development and utilization of hydrogen energy in the future. 
Author Contributions: Conceptualization, Y.C. and Q.T.; data curation, Y.Y., L.Y. (Lihua Yang) and J.C. (Jiaen Cheng); formal analysis, Y.Y., Q.T., J.C. (Jian Cao) and M.W.; funding acquisition, Y.C., Q.T., L.Y. (Lihua Yang), H.F., P.Z. and J.Y.; investigation, Y.Y., J.C. (Jiaen Cheng), X.L., H.F. and M.W.; methodology, L.Y. (Lihua Yang) and X.L.; project administration, J.Y.; resources, P.Z. and L.Y. (Lili Yang); supervision, J.Y.; validation, J.C. (Jian Cao); visualization, P.Z.; writing-original draft, Y.C.; writing-review and editing, Y.C., Q.T. and P.Z. All authors have read and agreed to the published version of the manuscript.

Funding: This research was funded by the National Natural Science Foundation of China (under grant Nos. 11904119, 11904129), the Central Government Guided Local Science and Technology Development Fund for Basic Research of Jilin Province (No. 202002015JC), the Program for the development of Science and Technology of Jilin province (20190103039JH, 20190701021GH), the Open Project of State Key Laboratory of Superhard Materials (Jilin University) (201911), the China Postdoctoral Science Foundation (No. 2016M601374), the National Key R\&D Program of China (2018YFA0703400), and the National Youth Program Foundation of China (61705020).

Data Availability Statement: All relevant data are contained in the present manuscript.

Conflicts of Interest: The authors declare no conflict of interest.

\section{References}

1. Schlapbach, L.; Züttel, A. Hydrogen-storage materials for mobile applications. Nature 2001, 414, 353-358. [CrossRef] [PubMed]

2. Wang, X.C.; Carlsson, J.M.; Domen, K.; Maeda, K.; Thomas, A.; Takanabe, K.; Xin, G.; Antonietti, M. A metal-free polymeric photocatalyst for hydrogen production from water under visible light. Nat. Mater. 2009, 8, 271-275. [CrossRef] [PubMed]

3. Liu, C.; Li, F.; Ma, L.P.; Cheng, H.M. Advanced materials for energy storage. Adv. Mater. 2010, 22, E28-E62. [CrossRef]

4. Kanan, M.W.; Nocera, D.G. In Situ Formation of an Oxygen-Evolving Catalyst in Neutral Water Containing Phosphate and Co ${ }^{2+}$. Science 2008, 321, 1072-1075. [CrossRef] [PubMed]

5. Khaselev, O.; Turner, J.A. A Monolithic Photovoltaic-Photoelectrochemical Device for Hydrogen Production via Water Splitting. Science 1998, 280, 425-427. [CrossRef] [PubMed]

6. Shi, Y.M.; Zhang, B. Recent advances in transition metal phosphide nanomaterials: Synthesis and applications in hydrogen evolution reaction. Chem. Soc. Rev. 2016, 45, 1529-1541. [CrossRef]

7. Sun, H.M.; Yan, Z.H.; Liu, F.M.; Xu, W.C.; Cheng, F.Y.; Chen, J. Self-Supported Transition-Metal-Based Electrocatalysts for Hydrogen and Oxygen Evolution. Adv. Mater. 2020, 32, 1806326. [CrossRef]

8. Zhang, Y.Q.; Ouyang, B.; Xu, J.; Jia, G.C.; Chen, S.; Rawat, R.S.; Fan, H.J. Rapid Synthesis of Cobalt Nitride Nanowires: Highly Efficient and Low-Cost Catalysts for Oxygen Evolution. Angew. Chem. Int. Edit. 2016, 55, 8670-8674. [CrossRef]

9. Vrubel, H.; Hu, X.L. Molybdenum boride and carbide catalyze hydrogen evolution in both acidic and basic solutions. Angezw. Chem. Int. Edit. 2012, 51, 12703-12706. [CrossRef]

10. Wang, X.F.; Tai, G.A.; Wu, Z.H.; Hu, T.S.; Wang, R. Ultrathin molybdenum boride films for highly efficient catalysis of the hydrogen evolution reaction. J. Mater. Chem. A 2017, 5, 23471-23475. [CrossRef]

11. Lu, W.B.; Liu, T.T.; Xie, L.S.; Tang, C.; Liu, D.N.; Hao, S.; Qu, F.L.; Du, G.; Ma, Y.J.; Asiri, A.M.; et al. In Situ Derived CoB Nanoarray: A High-Efficiency and Durable 3D Bifunctional Electrocatalyst for Overall Alkaline Water Splitting. Small 2017, 13, 1700805. [CrossRef]

12. Zhang, P.L.; Wang, M.; Yang, Y.; Yao, T.Y.; Han, H.X.; Sun, L.C. Electroless plated Ni-B films as highly active electrocatalysts for hydrogen production from water over a wide $\mathrm{pH}$ range. Nano Energy 2016, 19, 98-107. [CrossRef]

13. Li, H.; Wen, P.; Li, Q.; Dun, C.C.; Xing, J.H.; Lu, C.; Adhikari, S.; Jiang, L.; Carroll, D.L.; Geyer, S.M. Earth-Abundant Iron Diboride $\left(\mathrm{FeB}_{2}\right)$ Nanoparticles as Highly Active Bifunctional Electrocatalysts for Overall Water Splitting. Adv. Energ. Mater. 2017, 7, 1700513. [CrossRef]

14. Zhang, T.; Song, F.Z.; Qian, Y.Q.; Gao, H.; Shaw, J.; Rao, Y. Elemental Engineering of High-Charge-Density Boron in Nickel as Multifunctional Electrocatalysts for Hydrogen Oxidation and Water Splitting. ACS Appl. Energy Mater. 2021, 4, 5434-5442. [CrossRef]

15. Ma, X.Y.; Zhang, S.H.; He, Y.; He, T.; Li, H.J.; Zhang, Y.H.; Chen, J.Y. Boron and phosphorus co-doped NiVFe LDHs@NF as a highly efficient self-supporting electrocatalyst for the hydrogen evolution reaction. J. Electroanal. Chem. 2021, 886, 115107. [CrossRef]

16. Gu, W.S.; Pan, Z.Q.; Tao, H.; Guo, Y.L.; Pu, J.; Zhong, C.L.; Li, J.C.; Ye, C.Q.; Zhou, Q.W. Boron-modulated surface of hollow nickel framework for improved hydrogen evolution. Chem. Commun. 2021, 57, 2404-2407. [CrossRef] [PubMed]

17. Guan, J.T.; Zhang, X.R.; Li, Q.Y.; Deng, K.M.; Jena, P.; Kan, E.J. Two-dimensional metal-free boron chalcogenides $B_{2} X_{3}(X=S$ Se and $\mathrm{Te}$ ) as photocatalysts for water splitting under visible light. Nanoscale 2021, 13, 3627-3632. [CrossRef] [PubMed]

18. Han, C.; Li, W.J.; Wang, J.Z.; Huang, Z.G. Boron leaching: Creating vacancy-rich Ni for enhanced hydrogen evolution. Nano Res. 2021, 14, 1-9. [CrossRef] 
19. Guo, X.W.; Chen, Z.C.; Huang, Y.P.; Lv, H.; Wang, Y.R.; Sun, L.Z.; Song, K.; Liu, B. Mesoporous Palladium-Boron-Sulfur Alloy Nanospheres for Efficient Hydrogen Evolution. Inorg. Chem. 2021, 60, 4380-4384. [CrossRef]

20. Cheng, Z.F.; Pi, Y.C.; Shao, Q.; Huang, X.Q. Boron-doped amorphous iridium oxide with ultrahigh mass activity for acidic oxygen evolution reaction. Sci. China Mater. 2021, 64, 1-6. [CrossRef]

21. Chen, K.; Wang, Z.M.; Wang, L.; Wu, X.Z.; Hu, B.J.; Liu, Z.; Wu, M.H. Boron Nanosheet-Supported Rh Catalysts for Hydrogen Evolution: A New Territory for the Strong Metal-Support Interaction Effect. Nano-Micro Lett. 2021, 13, 138. [CrossRef] [PubMed]

22. Liu, Y.F.; Ali, R.; Ma, J.; Jiao, W.; Yin, L.J.; Mu, C.H.; Jian, X. Graphene-Decorated Boron-Carbon-Nitride-Based Metal-Free Catalysts for an Enhanced Hydrogen Evolution Reaction. ACS Appl. Energy Mater. 2021, 4, 3861-3868. [CrossRef]

23. Bat-Erdene, M.; Batmunkh, M.; Sainbileg, B.; Hayashi, M.; Bati, A.S.R.; Qin, J.D.; Zhao, H.J.; Zhong, Y.L.; Shapter, J.G. Highly Dispersed Ru Nanoparticles on Boron-Doped $\mathrm{Ti}_{3} \mathrm{C}_{2} \mathrm{~T}_{\mathrm{x}}$ (MXene) Nanosheets for Synergistic Enhancement of Electrocatalytic Hydrogen Evolution. Small 2021, 17, 2102218. [CrossRef]

24. Chen, Y.L.; Yu, G.T.; Chen, W.; Liu, Y.P.; Li, G.D.; Zhu, P.W.; Tao, Q.; Li, Q.J.; Liu, J.W.; Shen, X.P.; et al. Highly Active, Nonprecious Electrocatalyst Comprising Borophene Subunits for the Hydrogen Evolution Reaction. J. Am. Chem. Soc. 2017, 139, 12370-12373. [CrossRef]

25. Tao, Q.; Chen, Y.L.; Lian, M.; Xu, C.H.; Li, L.; Feng, X.K.; Wang, X.; Cui, T.; Zheng, W.T.; Zhu, P.W. Modulating Hardness in Molybdenum Monoborides by Adjusting an Array of Boron Zigzag Chains. Chem. Mater. 2018, 31, 200-206. [CrossRef]

26. Kiessling, R. The crystal structures of molybdenum and Tungsten borides. Acta Chem. Scand. 1947, 1, 893-916. [CrossRef]

27. Kayhan, M.; Hildebrandt, E.; Frotscher, M.; Senyshyn, A.; Hofmann, K.; Alff, L.; Albert, B. Neutron diffraction and observation of superconductivity for tungsten borides, $\mathrm{WB}$ and $\mathrm{W}_{2} \mathrm{~B}_{4}$. Solid State Sci. 2021, 14, 1656-1659. [CrossRef]

28. Henschel, A.; Binnewies, M.; Schmidt, M.; Kçppe, R.; Burkhardt, U.; Grin, Y. Tungsten Borides: On the Reaction of Tungsten with Boron(III) Bromide. Chem. Eur. J. 2018, 24, 10109-10115. [CrossRef] [PubMed]

29. Kumar, B.; Kumar, S.; Ganguli, A.K. Surface decoration through electrostatic interaction leading to enhanced reactivity: Low temperature synthesis of nanostructured chromium borides (CrB and $\left.\mathrm{CrB}_{2}\right)$. J. Solid State Chem. 2013, 200, 117-122.

30. Homolová, V.; Čiripová, L.; Kepič, J. Isothermal Section of the B-Cr-Fe System at 873 K. J. Phase Equilib. Diffus. 2019, 40, 79-85. [CrossRef]

31. Hartman, P.; Perdok, W.G. On the Relations Between Structure and Morphology of Crystals. I. Acta Cryst. 1955, 8, 49-52. [CrossRef]

32. Hartman, P.; Perdok, W.G. On the Relations Between Structure and Morphology of Crystals. II. Acta Cryst. 1955, 8, 521-524. [CrossRef]

33. Hartman, P. The Attachment Energy as a Habit Controlling Factor III. Application to Corundum. J. Cryst. Growth 1980, 49, 166-170. [CrossRef]

34. Park, H.; Encinas, A.; Scheifers, J.P.; Zhang, Y.; Fokwa, B.P.T. Boron-Dependency of Molybdenum Boride Electrocatalysts for the Hydrogen Evolution Reaction. Angew. Chem. Int. Ed. 2017, 56, 5575-5578. [CrossRef] [PubMed]

35. Vinoth, S.; Das, H.T.; Govindasamy, M.; Wang, S.F.; Alkadhi, N.S.; Ouladsmane, M. Facile solid-state synthesis of layered molybdenum boride-based electrode for efficient electrochemical aqueous asymmetric supercapacitor. J. Alloy. Compd. 2021, 877, 160192. [CrossRef]

36. Chrzanowska-Giżyńska, J.; Denis, P.; Woźniacka, S.; Kurpaska, Ł. Mechanical properties and thermal stability of tungsten boride films deposited by radio frequency magnetron sputtering. Ceram. Int. 2018, 44, 19603-19611. [CrossRef]

37. Biesinger, M.C.; Payne, B.P.; Grosvenor, A.P.; Lau, L.W.M.; Gerson, A.R.; Smart, R.S.C. Resolving surface chemical states in XPS analysis of first row transition metals, oxides and hydroxides: Cr, Mn, Fe, Co and Ni. Appl. Surf. Sci. 2011, 257, 2717-2730. [CrossRef]

38. Korotin, M.A.; Zhidkov, I.S.; Kukharenko, A.I.; Cholakh, S.O.; Kamenetskikh, A.S.; Gavrilov, N.V.; Kurmaev, E.Z. Interfacial reactions in $\mathrm{Al}_{2} \mathrm{O}_{3} / \mathrm{Cr}_{2} \mathrm{O}_{3}$ layers: Electronic structure calculations and X-ray photoelectron spectra. Thin Solid Films 2018, 665, 6-8. [CrossRef]

39. Moulder, J.F.; Stickle, W.F.; Sobol, P.E.; Bomben, K.D. Handbook of X-ray Photoelectron Spectroscopy. In Perkin-Elmer Corporation Physical Electronics Division; Perkin-Elmer: Eden Prairie, MN, USA, 1992; p. 261.

40. Luo, J.Y.; Gong, L.; Tan, H.D.; Deng, S.Z.; Xu, N.S.; Zeng, Q.G.; Wang, Y. Study of the catalyst poisoning and reactivation of Pt nanoparticles on the surface of $\mathrm{WO}_{3}$ nanowire in gasochromic coloration. Sensor. Actuat. B Chem. 2012, 171-172, 1117-1124. [CrossRef]

41. Li, Q.J.; Wang, L.N.; Ai, X.; Chen, H.; Zou, J.Y.; Li, G.D.; Zou, X.X. Multiple crystal phases of intermetallic tungsten borides and phase-dependent electrocatalytic property for hydrogen evolution. Chem. Commun. 2020, 56, 13983-13986. [CrossRef]

42. Zhang, M.L.; Zhang, Y.Q.; Ye, L.; Guo, B.W.; Gong, Y.Q. Hierarchically constructed Ag nanowires shelled with ultrathin Co-LDH nanosheets for advanced oxygen evolution reaction. Appl. Catal. B Environ. 2021, 298, 120601. [CrossRef]

43. Xie, X.Q.; Liu, J.P.; Gu, C.N.; Li, J.J.; Zhao, Y.; Liu, C.S. Hierarchical structured CoP nanosheets/carbon nanofibers bifunctional eletrocatalyst for high-efficient overall water splitting. J. Energ. Chem. 2022, 64, 503-510. [CrossRef]

44. Shamloofard, M.; Shahrokhian, S.; Amini, M.K. Mesoporous nanostructures of NiCo-LDH $/ \mathrm{ZnCo}_{2} \mathrm{O}_{4}$ as an efficient electrocatalyst for oxygen evolution reaction. J. Colloid Interf. Sci. 2021, 604, 832-843. [CrossRef]

45. Kim, C.; Kim, S.H.; Lee, S.; Kwon, I.; Kim, S.H.; Kim, S.; Seok, C.; Park, Y.S.; Kim, Y. Boosting overall water splitting by incorporating sulfur into NiFe(oxy) hydroxide. J. Energ. Chem. 2022, 64, 364-371. [CrossRef] 
46. Chen, Y.L.; Rong, J.S.; Tao, Q.; Xing, C.; Lian, M.; Cheng, J.E.; Liu, X.Y.; Cao, J.; Lv, S.Q.; Yang, L.L.; et al. Modifying microscopic structures of $\mathrm{MoS}_{2}$ by high pressure and high temperature used in hydrogen evolution reaction. Electrochim. Acta 2020, 357, 136868. [CrossRef]

47. Wu, Z.P.; Lu, X.F.; Zang, S.Q.; Lou, X.W. Non-Noble-Metal-Based Electrocatalysts toward the Oxygen Evolution Reaction. Adv. Funct. Mater. 2020, 30, 1910274. [CrossRef]

48. Wu, L.L.; Chen, X.H.; Zhang, Q.; Luo, J.; Fu, H.C.; Shen, L.; Luo, H.Q.; Li, N.B. Formation of hierarchical NiFe Prussian blue analogues/Prussian blue on nickel foam for superior water oxidation. Appl. Surf. Sci. 2021, 567, 150835. [CrossRef]

49. Zhang, M.L.; Wang, J.L.; Zhang, Y.P.; Ye, L.; Gong, Y.Q. Ultrafine CoRu alloy nanoparticles in situ embedded in $\mathrm{Co}_{4} \mathrm{~N}_{\mathrm{N}}$ porous nanosheets as high-efficient hydrogen evolution electrocatalysts. Dalton Trans. 2021, 50, 2973-2980. [CrossRef] [PubMed]

50. Wang, T.T.; Guo, X.S.; Zhang, J.Y.; Xiao, W.; Xi, P.X.; Peng, S.L.; Gao, D.Q. Electronic structure modulation of NiS 2 by transition metal doping for accelerating the hydrogen evolution reaction. J. Mater. Chem. A 2019, 7, 4971-4976. [CrossRef] 